\title{
Biofertilizer and chemical fertilizer induced changes in cyto-morphological and biochemical constituents of Foeniculum vulgare Mill.
}

\author{
Girjesh Kumar, Rajani Singh*, Radha Mishra \\ Naithani Plant Genetics Laboratory, Department of Botany, University of Allahabad, Prayagraj 211002, Uttar Pradesh, India
}

Received: September 07, 2019 Revised: April 06, 2020 Accepted: April 07, 2020 Published: April 09, 2020

\section{*Corresponding Author:} Rajani Singh Email: singh.rajani1995@gmail. com

\begin{abstract}
The agriculture sector requires a revolutionary alternative that makes crop production high and elicits less ill-effects on the environment. At present, agriculture area facade the challenge of low yield of many agronomic crops which lead to economic losses. Experimentally, it is proved that fertilizer use can boost yield two three times more in spite of other factors unchanged. But surplus and unbalanced usage of these soil supplements like fertilizers and irrigation causes serious problems to our soils like water logging and formation of saline soils and ultimately lead to denatured soil. This situation can be alleviated through the use of eco-friendly biofertilizer. So the present appraisal scrutinizes the effect of fertilizer Ammonium Phosphate Sulphate (APS) and biofertilizer (Agrozyme) on the cytology, morphology and pigment constituents of the Foeniculum vulgare Mill. and to trace out a safer crop enhancer among the two. The results revealed that fertilizer expelled to be more chromotoxic and mito-inhibitory at higher concentration in comparison to biofertilizer. Fertilizer negatively affects the plant's mitotic index while biofertilizer enhances mitotic index parallel to the increasing concentration. Biofertilizer shows positive effect on the germination, survival and plant growth while fertilizer shows this elevation effect at lower concentration. The biochemical constituents (photosynthetic pigments) are greatly affected by higher concentration of both the treatments. The treated system shows various anomalies such as stickiness, precocious movement, loop formation at metaphasic stage and stickiness, laggard and bridge etc at anaphasic stage. Since, biofertilizers area much safer as compared to fertilizers and it also enhances the qualitative and quantitative traits, therefore it could be used in agro-system to obtain sustainable crop upgradation.
\end{abstract}

KEYWORDS: Active Mitotic Index (AMI), agrozyme, ammonium phosphate sulfate, Foeniculum vulgare, root meristems.

\section{INTRODUCTION}

Herbs and spices are plant-derived seasonings used for culinary resolves. In addition to making food taste good, culinary spices have been used as food stabilizers and for their health-enhancing qualities for eras [1]. Spices stimulate appetite and create visual appeals to food [2]. The use of spices in culinary preludes recorded history and is said to have been an vital part of local dishes in South Asia and the Middle East as far back as 2000 BCE [3]. From the dawn of civilization, there is evidence that humans were using spices for their health properties as well as for their ability to create zing in food. These are functional foods that can be verified to have a quantifiable role on certain target functions in the body beyond elementary nutritional requirements. Spices occur in a variety of flavour, colour, and aroma paying a wide range of nutrients to foods [4]. They augment and balance flavour in foods with no waning effect on the organoleptic values of the food [1]. Herbs and spices elaborate secondary metabolites that form part of the plants' chemical defence. These secondary metabolites obtained from spices also possess noticeable pharmacological and medicinal properties [5]. The importance of spices is accentuated by the fact that they are still found in $40 \%$ of drugs prescribed till date [4]. Spices and herbs are esteemed for their latent health attributes. They are revered to have optimistic effects in the cure of countless diseases, predominantly immedicable ones such as cancer, diabetes, and cardiovascular diseases [1]. Nutrition and health are tortuously linked and the ability of nutrition (in this case, nutrients from spices) to reduce the risk of diseases has

Copyright: () The authors. This article is open access and licensed under the terms of the Creative Commons Attribution License (http://creativecommons.org/licenses/by/4.0/) which permits unrestricted, use, distribution and reproduction in any medium, or format for any purpose, even commercially provided the work is properly cited. Attribution - You must give appropriate credit, provide a link to the license, and indicate if changes were made. 
attracted the scientists to create ways for increasing production of spices so that farmers incentivised to cultivate spices on their agricultural land. This revolutionises the role of fertilizers to enhance the production of crop. But along with increased yield of crop it also deteriorated the quality of soil when used in increased amount in lure of more and more yield of crop. It also creates problems of bioaccumulation in food crops which causes waning effect on health. This tend agriculturist towards the biofertilizers. Biofertilizers are living microorganism or certain plants (like azolla) that are used to check the declining quality of soil as well as to increase production of crops. Earlier many studies were concluded about the role of fertilizers and biofertilizers in crop production.

The present experiment is designed to devise the role of fertilizers (Ammonium phosphate sulphate) and bio fertilizers (agrozyme) on the cytomorphological and biochemical aspects of plant and also to investigate the impact of these in plant productivity for achieving the sustainable development goal to promote organic farming and sustainable environment for the future.

\section{MATERIAL AND METHODS}

\section{Procurement of seeds}

Pure inbred seeds of Fennel (Foeniculum vulgare L.) were obtained from SHUATS, Naini, Prayagraj.

\section{Seed germination}

Fresh healthy seeds of fennel were taken and were soaked with water on Petriplates. Within two to four days, seeds germinated giving off healthy roots.

\section{Treatment}

For the treatment, roots were separated into various sets and dipped in graded aqueous concentration (prepared by using Dilution method) for 4 different concentrations viz. $0.5 \%, 1 \%$, $1.5 \%$, and $2 \%$ of APS and agrozyme solution, respectively for duration of three hours along with control. Agrozyme which contains the seaweed constituents of Fucus vesiculosus and Ascophyllum nodosum [6].

\section{Fixation}

After treatment, the roots were fixed in Carnoy's Fixative (Alcohol: Glacial Acetic Acid in 3:1 ratio) at an appropriate time. After 24 hours, roots were transferred in 90\% alcohol for preservation and were ready for cytological observation.

\section{Slide Preparation}

The hydrolysis of root tips was done in $1 \mathrm{~N} \mathrm{HCl}$ at $60^{\circ} \mathrm{C}$ temperature. After that, the roots were thoroughly washed under running water, followed by staining using $2 \%$ acetocarmine stain. These darkly stained root tips were excised and used for slide preparation by Squash technique method. Slides were observed under microscope and photo micrograph was done using PCTV software.

\section{Formula used for calculation}

Number of dividing cells

Active Mitotic index $(\mathrm{AMI} \%)=\frac{\text { Total number of dividing cells }}{\text { Total number of cells observed }} \times 100$

$\underset{\text { Potal Abnormality }}{\text { Percentage }(\mathrm{TAB})}=\frac{\text { Total Number of Abnormal cells }}{\text { Total number of cells observed }} \times 100$

The AMI\% and TAB\% of each concentration were computed by obtaining ten microscopic views for each slide. For each respective concentration five slides were recorded. Data was further utilised to generate statistical results. For this, SPSS 16.0 software was used followed by One Way analysis of Variance (ANOVA) and Duncan Multiple range Test $(\mathrm{p}<0.05)$. Graphs were plotted by the assistance of Sigma Plot 10.0 software.

\section{Morphological analysis}

The morphological parameters were taken such as germination (7 days), survival percentage (14 days) and plant height $(\mathrm{cm})$ for studying the impact of biofertilizer and fertilizer. To calculate germination percentage, the total number of germinated seeds was counted and it divided by total number of seeds. After 14 days, the remaining seedlings were counted for survival percentage.

\section{Biochemical Analysis}

For Biochemical analysis the $20 \mathrm{mg}$ of fresh leaves were taken from plant material, which was immediately extracted and assayed.

\section{Pigment Analysis}

The photosynthetic pigment content was quantified using $80 \%$ Acetone extract method and optical density was taken at $663 \mathrm{~nm}, 646 \mathrm{~nm}$ and 470nm for Chlorophyll $a$, chlorophyll $b$ and carotenoids percentages were computed there upon according to method described by Lichtenthaler and Welburn [7].

\section{RESULTS}

Fertilizers are used for supplying the micro and or macro elements to the cultivated plants in order to increase crop productivity. So the present investigation elucidates the comparative effect of fertilizer and biofertilizer on the root meristem of Fennel for studying chromosomal behavior. Morphology of the plant is also affected followed by biochemical aspects.

\section{Effect on the Mitotic index and abnormality percentage}

As biofertilizer contains living cells of efficient strains of $\mathrm{N}_{2}$ fixing, phosphorous solublizing or cellulolytic microorganisms which provide and enhance all the essential nutrient elements 
for the plant. In the present experiment biofertilizer accelerates the mitotic index of fennel while in comparison to this chemical fertilizer shows declined mitotic index at high concentration (Fig. 2). Data in table 1 summarized the effect of agrozyme and APS on fennel.In the control plant of fennel the AMI recorded was $12.33 \pm 0.16 \%$. The AMI was increased at the lower doses of agrozyme and APS. In APS, AMI first displayed an increasing trend at $0.5 \%$ and $1.0 \%$ concentration giving the values $12.62 \pm 0.24 \%$ and $12.89 \pm 0.12 \%$ respectively. However at the highest concentration ( $2 \%$ ) of APS, it decreased to $10.38 \pm 0.22 \%$. But in the case of agrozyme along with increase in concentration, the AMI increases until the highest dose with values $12.92 \pm 0.25 \%$ to $14.67 \pm 0.21 \%$ for $0.5 \%$ to $2 \%$ concentration, respectively.

Abnormalities in root tips of fennel were dose dependent. The control plant deciphers normal chromosomal organization as $2 n=22$ at metaphase (Fig. 1A) and normal segregation (Fig. 1B) at anaphase. Different chromosomal aberrations were detected at different doses as presented in Fig lC-I. Various chromosomal anomalies were encountered at varying concentrations viz stickiness, precocious, laggards and bridges etc. Comparative account of $\mathrm{TAB} \%$ shown via Fig. 1 explains that anomalies percentage is more conspicuous in APS as compared to agrozyme. In agrozyme at $0.5 \%$ the TAB\% was recorded as $1.03 \pm 0.12$ while in APS it was $2.24 \pm 0.18 \%$. Further at $2 \%$ the

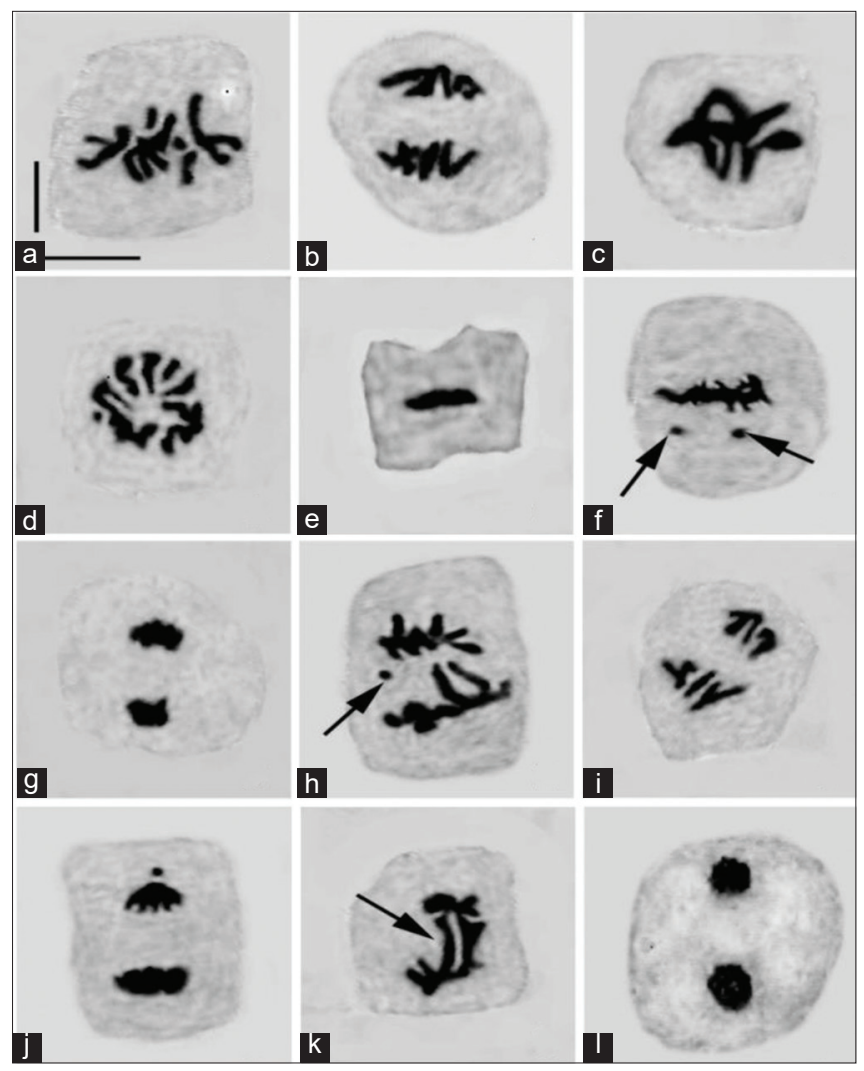

Figure 1: Legends of figure- a. Normal metaphase $(2 n=22)$, b. Normal anaphase (11:11 separation), c. Loop formation at metaphase, d. Scattering at metaphase, e. Stickiness at metaphase, f. Two precocious chromosome at metaphase, g. Stickiness at anaphase h.One laggard chromosome at anaphase, i.Unorientation at anaphase, j.forward chromosome at anaphase, k.Bridge formation at anaphase, I. Normal telophase. [Scale bar: Length $=9.36 \mu \mathrm{m}$, breadth $=7.26 \mu \mathrm{m}$ ]

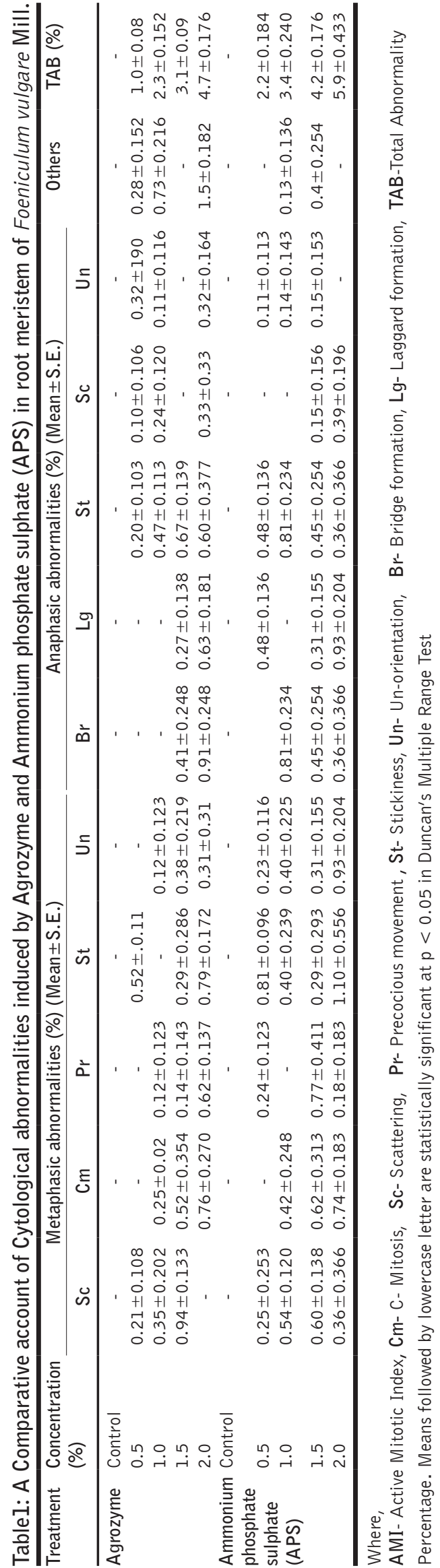


$\mathrm{TAB} \%$ was seen more prominent as comparison to agrozyme i.e. $5.93 \pm 0.43 \%$ and $4.70 \pm 0.17 \%$, respectively.

\section{Influence on the morphological parameters}

\section{Germination and Survival percentage}

The results revealed the significant effects of fertilizer and biofertilizer on germination percentage. The control sets exhibited $95.33 \pm 1.26 \%$ which was elevated as the concentration of agrozyme increases. In agrozyme, at $0.5 \%$ and $1.0 \%$ the germination percentage was $96.45 \pm 1.83 \%$ and $98.02 \pm 1.02 \%$, respectively. On the opposite in APS, germination percentage shows reciprocal relationship to the treated concentrations (Fig. 3A). The survivability percentage also shows same relationship with agrozyme and APS as above. At $0.5 \%$ and $1.0 \%$ of agrozyme the survivability percentage was found to

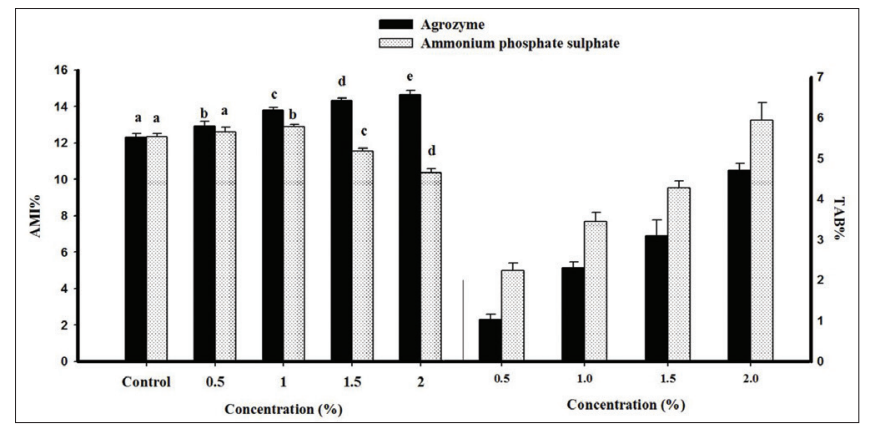

Figure 2: Comparative account of $A M I \%$ and $T A B \%$ induced by agrozyme and APS in the root meristem of fennel (Foeniculumvulgare Mill.)

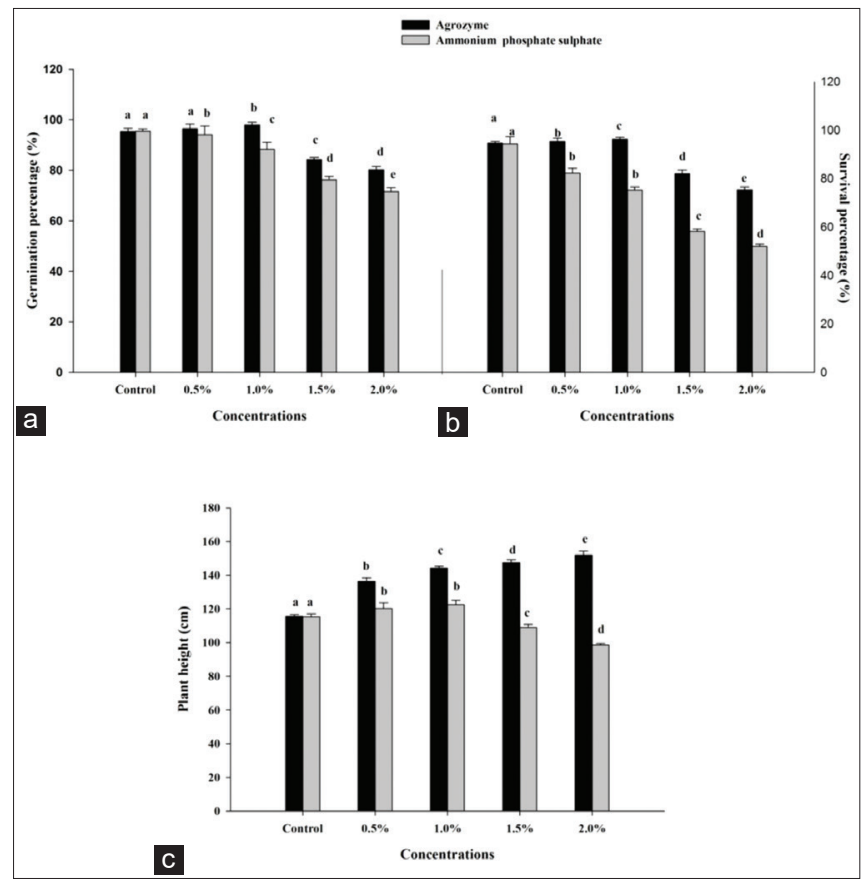

Figure 3: Comparative account of germination, survival and plant height percentages of fennel (Foeniculumvulgare Mill.) induced by agrozyme and APS. be $95.47 \pm 1.32 \%$ and $96.33 \pm 0.78 \%$. At highest concentration the survivability percentage was declined to $75.43 \pm 1.17 \%$ and $52.12 \pm 0.81 \%$ in agrozyme and APS respectively (Fig. 3B).

\section{Plant height}

From the obtained data it was noticed that biofertilizer and fertilizer both had a significant impact on plant height. Continued stimulation with respect to increase in concentration was noticed in case of agrozyme and highest value of $152.01 \pm 2.45 \mathrm{~cm}$ plant height was recorded at $2 \%$. In case of APS the plant height was increased at lower concentration i.e. $0.5 \%$. However, a sharp decline to $98.67 \pm 0.80 \mathrm{~cm}$ at higher concentration (2\%) witnessed (Fig.3C).

\section{Effect on the pigment content}

Estimation of photosynthetic pigment shows variation in control and treated sets. The chlorophyll $a$ and $b$ were recorded to be $0.98 \pm 0.06,0.34 \pm 0.02$ in control sets whereas carotenoid content was estimated to be $0.32 \pm 0.01$. A dose dependent increase in photosynthetic pigment was registered in agrozyme treated sets at all doses and at $2.0 \%$ concentration the amount of chla, $b$ and carotenoid was recorded to be $1.26 \pm 0.01,0.73 \pm 0.04$ and $0.52 \pm 0.03$, respectively as mentioned in Fig. 4 A,B,C. However in case of APS, a dose dependent decrement was noticed with respect to its higher three concentrations except for lowest concentration i.e. $0.5 \%$ APS where, an increase in photosynthetic pigments content was observed. At highest concentration $(2.0 \%)$, quantified chlorophyll content was recorded as0.68 \pm 0.05 (chla), $0.18 \pm 0.06$ (chlb) and $0.21 \pm 0.02$ (carotenoid), as (Fig. 4 A,B,C).

\section{DISCUSSION}

\section{Cytological analysis}

Analysis of variance shows that biofertilizer and fertilizer have a significant effect on AMI. The use of biofertilizer is considered

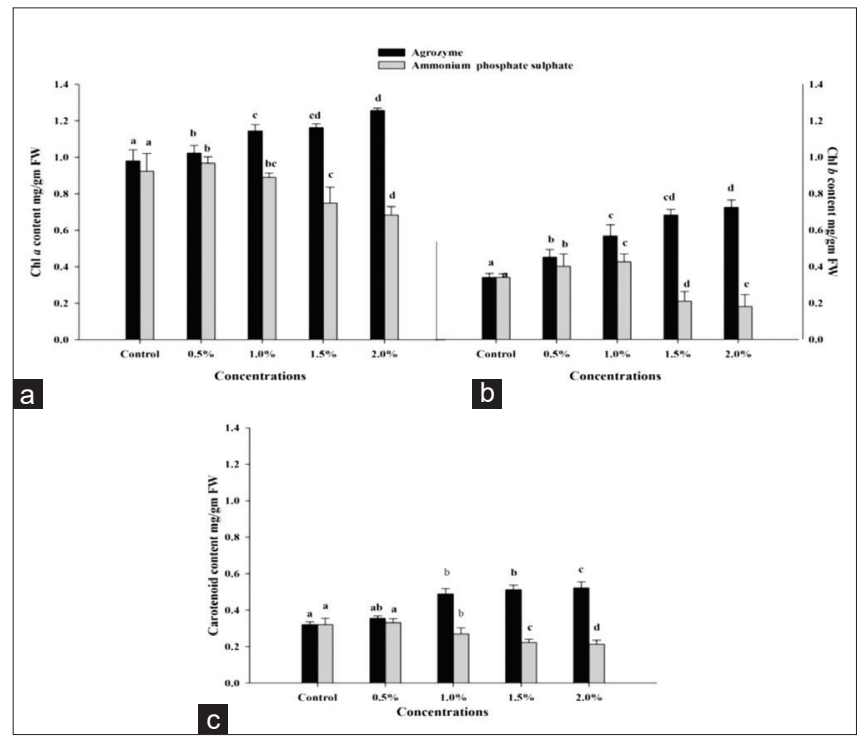

Figure 4: Comparative account of chlorophyll and carotenoid contents in fennel (Foeniculumvulgare Mill.) induced by agrozyme and APS 
to be one of the most important factors to increase crop yield. As from the above result biofertilizer efficiently increases the plant mitotic index, which shows that it provides nutrient element which participate in nutrient cycling and benefits crop productivity [8]. It may be due to theincrease in metaphase and anaphase percentage was observed, perhaps due to lengthening of their duration $[9,10]$. Positive responses for organic fertilizers have also been confirmed in chickpea $[11,12]$. Main benefits of biofertilizers are, supply of microelement or organic matter and cheap source of nutrients. On the counterpart APS cause mitodeaccelerating effect on the AMI at the higher concentration. This illustrates that the judicious utilization of chemical fertilizer should be used for the field crop. The lowering of AMI \% can be attributed to inhibition of DNA synthesis at S- phase [13]. The mitodecelerating effect of fertilizers on AMI at higher dose was also reported by Abraham and Nair [14] in Viciafaba, Bhatta and Sakya [15] in Allium cepa. Chromosomal anomalies show intense increases in both the cases, but the chromosomal disturbance was more obvious in the case of APS. It might have occurred due the binding of ammonium ion to the DNA which causes inhibition of cell cycle. These synthetic chemicals also aggravate chromosomal identity [16]. Abraham [17] found that fertilizers produced a significant increase in chromosomal aberrations. Similar observations were also obtained by Kumar and Naseem [18], Kumar and Gupta [19]. There are many abnormalities induced through fertilizer and biofertilizer but stickiness was the prominent abnormality found at various doses. Stickiness might have caused due to entangling of the chromosomes together. Stickiness (Fig.le $\& 1 \mathrm{~g})$ was found in both metaphase and anaphase of mitosis. Chromosome stickiness leads to inactivation of DNA replication, increased chromosomal contraction and condensation or nucleoproteins probably leading to cell death [20].

Due to abnormal function of spindle the chromosome fails to attach with kinetochore resulting into improper chromosomal division which leads to the formation of loop (Fig. lc)

Precocious movement of chromosomes is characterized as migration of normal chromosome at equatorial plate, leading to seclusion of chromatid from whole cluster of chromosomes. Precocious movement (Fig. If) denotes of early terminalisation of chromosome or dysfunctioning of spindle fibre. Laggard chromosome (Fig. 1h) occurred due to stickiness of chromosome or might be depending upon the moving speed and process of an individual chromosome differing from normal ones [21]. Bridges (Fig. 1k) might have resulted due to enhanced activity of fertilizer or biofertilizer caused breakage and reunion of chromosomes [22] or may be due to sticky chromosomes. Cytological explorations inferred that although fertilizers affected plants efficiently but it also increased the chance of environmental hazard. Comparatively, bio fertilizers are ecofriendly and sustainable substitute.

\section{Morphological analysis}

On the germination percentage APS shows negative effect. As the concentration increases it causes decline in the germination percentage. From APS ammonium ion might be amenders in the seed coats and internal tissues which reduce germination or cause unavailability of growth hormones (gibberellin and auxin) and water by making seed coat impermeable through binding between the cells. While biofertilizer in general enhanced the germination and other growth parameters which might be due to favorable soil physical environment created by the addition of organic manures [23]. Gupta et al. [24] reported that the use of organic manures are very effective due to the availability of N, P and K which improve soil health, soil ecology and soil environment supplying essential micronutrients. Further survivability of the plant fennel is also increased in the case of biofertilizer application at the lower concentration. Compost types and mineral fertilizers were more effective, as they provided more mineral elements such as $\mathrm{N}, \mathrm{P}, \mathrm{K}, \mathrm{Ca}, \mathrm{N}, \mathrm{Mg}$ and $\mathrm{C}$ for plant growth and development. Biofertilizers have an unique combination of all nutrients which might affect overall plant growth advancement. In contrast, chemical fertilizer shows lesser impact on the plant survivability, it might be that chemical fertilizer offers nutrients which are readily soluble in soil solution and thereby very rapidly available to plants but high inorganic ions availability effects physiological condition of the plant negatively. Chemical fertilizer shows instant effect and used up quickly because it contains few elements/ions but biofertilizers contain living microorganisms and other nutrients which provide all the contents needed for the plant division.

APS and agrozyme both one affect plant height positively. APS lower concentrations are beneficial for the plant but its higher amount is not applicable for the plant growth. Agrozyme accelerates the plant height of fennel that its height increase over the control sets. Rezvani et al. [25] also confirmed that biological fertilizer application in wheat resulted a significant effect on root and shoot length, but no significant effect was observed among cultivar types. In a study, which was conducted by Khoram Del et al. [26], it was shown that inoculation of Nigella seeds with biological fertilizer caused a significant increase in plant height, leaf area index, maximum dry matter accumulation and plant growth rate as compared with control. Muhammad [27] observed similar results with application of organic manure and compost in rice. The available nutrients might have helped in enhancing leaf area, which thereby resulted in higher photo-assimilates and more dry matter accumulation. These results are supported by the findings of Swarup and Yaduvanshi [28] and Yadana et. al. [29]. Kader et al. [30] reported a beneficial effect of Azospirillum on shoot length, which was attributed to production of growth stimulating hormones such as auxin, gibberellin and cytokinin.

\section{Biochemical analysis}

Chlorophyll contents are closely related with leaf photosynthetic rate. It takes part in biosynthetic processes occurring in the green part of the plants. Numerous studies have shown that chlorophyll content in plants increases sharply following fertilization with macroelements. The chemical fertilizer enhanced the chla, chlb and carotenoid content at lower concentration, while biofertilizer enhanced these 
photosynthetic pigments almost at all the concentrations. According to Skwaryło-Bednarz and Krzepiłko [31], the spare amount of NPK fertilizers is accompanied by the higher total chlorophyll content in plant material. According to Nalborczyk et al. [32] nitrogen fertilizer affects chlorophyll content in plants. Similarly biofertilizer significantly improved chlorophyll concentration in chilli [33] and in black gram [34]. This is because, $\mathrm{N}$ is the chief constituent of protein, essential for the formation of protoplasm, which leads to cell enlargement, cell division and ultimately resulting in increased plant growth. This positive effect of fertilizers on the photosynthetic pigments may be due to the improvement of chlorophyll formation, and photochemical efficiency of leaf [35]. Addition of biofertilizer might supply the essential elements to the plant by which plant synthesizes more chlorophyll. Similarly El Kinany [36] concluded that compost amendment has clearly increased chlorophyll amount and leaf mineral nutrition, particularly the macroelements. But APS at higher concentration reduces the chlorophyll concentration. These chemical fertilizers have been accredited to the obliteration of chlorophyll pigments and instability of the pigment protein complex which might be attributed to reduced synthesis of the main chlorophyll pigment complexes encoded by the chl. gene family [37], or to devastation of the pigment protein complexes which protect the photosynthetic apparatus, or to oxidative damage of chloroplast lipids and proteins, therefore development of chlorophyll $a, b$ and carotenoids decreases.

\section{CONCLUSION}

Aforementioned cytological, morphological and biochemical aspects in fennel evidently illustrate the activity of APS and agrozyme. This work discloses that agrozyme implements acceleration on mitotic division while APS acts as clastogenic at higher doses. APS causes higher anomalies with respect to agrozyme. Among both the treatments, bio-organic fertilizer induced lesser toxicity and increased the quality. Therefore it is advised to use fertilizer in least required concentration, while organic fertilizer should be promoted for sustainable agriculture.

\section{ACKNOWLEDGMENTS}

Authors express a deep sense of gratitude towards SHUATS, Naini, for availing the pure inbred seeds of Fennel. Special thanks to Head of Botany Department, University of Allahabad, for providing necessary facilities. Authors also thank the lab members of Plant Genetics Laboratory for valuable help.

\section{Competing Interest}

There is no Competing interest.

\section{Funding}

This research did not receive any specific grant from funding agencies in the public, commercial, or not-for-profit sectors.

\section{REFERENCES}

1. Kaefer, C.M. and Milner J.A., 2011. 17 Herbs and Spices in Cancer Prevention and Treatment. Lester Packer, Doctoral dissertation. 361.

2. Opara, E.I., and Chohan, M., 2014. Culinary herbs and spices: their bioactive properties, the contribution of polyphenols and the challenges in deducing their true health benefits. International Journal of Molecular Sciences.15, 19183-19202.

3. Tapsell, L.C., Hemphill, I., Cobiac, L., Sullivan, D.R., Fenech, M., Patch, C.S., Roodenrys, S., Keogh, J.B., Clifton, P.M., Williams, P.G. and Fazio, V.A.,2006. Health benefits of herbs and spices: the past, the present, the future. Med J Aust.185(4 Suppl),S4-24.

4. Mann, A., 2011. Biopotency role of culinary spices and herbs and their chemical constituents in health and commonly used spices in Nigerian dishes and snacks. African Journal of Food Science. 5, 111-124.

5. Newman, D.J., Cragg, G.M., 2012. Natural products as sources of new drugs over the 30 years from 1981 to 2010. Journal of Natural Products.75, 311-335.

6. Challen S. B. and Hemingway J. C., 1966. Growth of higher plants in response to feeding with seaweed extracts, Proc fifth Int Seaw Symp, Halifax. 359-367.

7. Lichtenthaler, H.K. and Wellburn, A.R., 1983. Determinations of total carotenoids and chlorophylls a and b of leaf extracts in different solvents. Biochemical Society transactions. 11,591-592.

8. Singh, J. S., Pandey, V. C. and Singh, D.P., 2011. Efficient soil microorganisms: a new dimension for sustainable agriculture and environmental development. Agric. Ecosyst. Environ. 140, 339-353.

9. Sobhi, H.M. and Haliem, A.S., 1990 Effect of herbicide rancho on root mitosis of Allium cepa. Egyptian journal of Botany. 33, 43-45.

10. Abdel Salam, A., Hassan, Z.E., Soliman, H.Z., and Khan, A., 1997. Differential mutagenic activities of two aromatic compounds due to side chains as revealed by cytological analysis and biochemical. Genetic indices. Egypt J. Genet. Cytol. 26, 121-142.

11. Ahmed, M.A. and Badr Elham, A., 2009. Effect of bio- and mineral phosphorus fertilizer on the growth, productivity and nutritional value of some chickpea cultivars (Cicer arietinumL.) in newly cultivated lands. Aust. J. Basic and Appli.Sci. 3, 4656 - 4664.

12. El- Kramany, M. F., Ibrahim, O.M., Badr Elham, A., and Ahmed, M.A.,2009. The deal effects of bio and organic fertilization on yield, its components and chemical constituents of two chickpea varieties. Egypt. J. Appl. Sci.14, 68-76.

13. Sudhakar, R., Gowda, N. and Venu,G., 2001.Mitotic abnormalities induced by silk dyeing industry effluents in the cells of Allium cepaL. Cytologia. 66, 235-239

14. Abraham, S. and Nair, R.B., 1989. Production of mitotic abnormalities by magnesium Sulphate in Vicia fabaL. Cytologia. 54, 559-653.

15. Bhatta, P. and Sakya, S.R., 2008. Study of mitotic activity and chromosomal behaviour in root meristem of Allium cepaL. treated with Magnesium sulphate. Ecological Society (ECOS), Nepal. Ecoprint. 15, 83-88.

16. Kumar, G. and Singh, S., 2016. Ameliorating responses of bio fertilizers over fertilizers in root meristems of barley (Hordeum vulgare L.). Chromosome Botany. 11,37-43.

17. Abraham, S., 1997 Studies on cytological changes induced by muriate of potash in Allium cepa L. Cytologia. 62, 291-294.

18. Kumar, G. and Naseem, S., 2011. Mitoclastic responses of biofertilizers and chemical fertilizers in root meristems of Trigonella foenum-graceumL. Chromosome Botany. 6, 121-124.

19. Kumar, G. and Gupta, P., 2008. Comparative genotoxic potential of inorganic fertilizers and bio fertilizers on meristematic cells of Capsicum annum L. Natl. Acad. Sci. Lett.31, 181-185.

20. Khanna, N., and Sharma, S., 2013. Allium Cepa Root Chromosomal Aberration Assay: A Review.1, 105-119.

21. Qian, X.W., 2004. Mutagenic effects of chromium trioxide on root tip cells of Vicia faba, Journal Zhejiang University Science. 5,1570-1576.

22. Haliem, A.,1990. Cytological effects of the herbicides sensor on root mitosis of Allium cepa L. Egypt J. Bot. 33, 93- 104.

23. Sarma, B., Gogoi, N., 2015.Germination and seedling growth of Okra (Abelmoschus esculentus L.) as influenced by organic amendments. Crop Journal of Soil and Sciences, 1-6.

24. Gupta, R.D., Kher, D., Jalali, V.K., 2005. Concept and its prospective in Jammu and Kashmir. Journal of Research, SKUAST-Jammu. 4,25-37.

25. Rezvani Moghadam, P., Amiri, M.B., Ghorbani, R., Fallahi, J. and 
Fallah pour, F., 2003. The effects of biological fertilizer effects on plant growth in various cultivar wheat. The articles of first national agriculture convention and stable development. Shiraz Azad University.1302-1314.

26. Khoram, D.S., Kochaki, A., Mahalati, M.N. and Ghorbani, R., 2008. The effect of biological fertilizers application on Nigella seeds growth indices. Iran Agriculture Investigation Magazine. 225-294.

27. Muhammad, I., 2008. Response of wheat growth and yield to various levels of compost and organic manure Pak. J. Bot.40,2135-2141

28. Swarup, A. and Yaduvanshi, N.P.S., 2000. Effect of Integrated nutrient management on soil properties and yield of rice in Alkali soils. J. Indian Soc. Soil Sci 48, 279-282.

29. Yadana, K.L., Aung, K.M., Takeo, Y. and Kazuo, O., 2009. The Effects of Green Manure (Sesbania rostrata) on the Growth and Yield of Rice J. Fac. Agr., Kyushu Univ.54, 313-319.

30. Kader, M.A., 2002. Effects of Azotobacter inoculant on the yield and nitrogen uptake by wheat. J. Biol. Sc. 2, 259-261.

31. Skwaryło-Bednarz, B. and Krzepiłko, A.,2009. Effect of Various Doses of NPK Fertilizers on Chlorophyll Content in the Leaves of Two Varieties of Amaranth (Amaranthus cruentus L.). Ecological Chemistry and Engineering.16,1373-1378.

32. Nalborczyk, E., Wróblewska, E., Marcinkowska, E. and
Roszewski, R.,1994 Amaranthus - prospect cultivation and utilization. Wyd. SGGW. Warszawa (in Polish).

33. Selvakumar, G. and Thamizhiniyan, P., 2011. The Effect of the Arbuscular Mycorrhizal (AM) Fungus Glomus intraradices on the Growth and Yield of Chilli (Capsicum annuum L.) Under Salinity Stress. World Appl. Sci. J. 14, 1209-1214.

34. Selvakumar, G., Reetha, S. and Thamizhiniyan, P., 2012. Response of Biofertilizers on growth, yield attributes and associated Protein Profiling changes of Blackgram (Vigna mungo L. Hepper. World Appl. Sci. 16, 1368-1374.

35. Al-Erwy, A.S., Bafeel,S.O. and Al-Toukhy, A.,2016. Effect of Chemical, Organic and Bio Fertilizers on Germination, Growth and yield of Wheat (Triticum aestivum L) Plants Irrigated With Sea Water. Seeds.10,100.

36. El Kinany, S., Achbani, E., Faggroud, M., Ouahmane, L., El Hilali, R., Haggoud, A. and Bouamri, R., 2019. Effect of organic fertilizer and commercial arbuscular mycorrhizal fungi on the growth of micropropagated date palm cv. Feggouss. Journal of the Saudi Society of Agricultural Sciences.18,411-417.

37. Nikolaeva, M.K., Maevskaya, S.N., Shugaev, A.G. and Bukhov, N.G.,2010. Effect of drought on chlorophyll content and antioxidant enzyme activities in leaves of three wheat cultivars varying in productivity. Russian J. Plant Physiol. 57, 87-95. 